\title{
Editorial
}

Gynecologic and

Obstetric Investigation

Published online: November 7, 2012

DOI: 10.1159/000343052

\section{WHO Reproductive Health Research at Crossroads}

This issue of Gynecologic and Obstetric Investigation is devoted to the WHO activities in Reproductive Health Research and Training for two reasons. Firstly, in 2012, the UNDP/UNFPA/WHO/World Bank Special Programme of Research, Development and Research Training in Human Reproduction (HRP) celebrates 40 years of innovation in the field of sexual and reproductive health. Secondly, in October 2012, Prof. Marleen Temmernan (Belgium) will succeed Dr. Mike Mbzivo to become the next director of the Department of Reproductive Health and Research (RHR) and of the HRP, both based at the WHO headquarters in Geneva, Switzerland.

HRP is the main instrument within the United Nations system for research in human reproduction, bringing together policy makers, scientists, health care providers, clinicians, consumers, and community representatives to identify and address priorities for research to improve sexual and reproductive health. HRP research helps people lead healthy sexual and reproductive lives, by strengthening the capacities of countries to provide quality information and services that enable people to protect their own sexual and reproductive health and that of their partners. As a global leader in reproductive health research, HRP supports and coordinates research on a global scale, synthesizes research through systematic reviews of literature, builds research capacity in low-income countries, and develops dissemination tools to make efficient use of ever-increasing research information.

The vision of the Department of RHR at the WHO headquarters is the attainment by all peoples of the high- est possible level of sexual and reproductive health. It strives for a world where all women's and men's rights to enjoy sexual and reproductive health are promoted and protected, and all women and men, including adolescents and those who are underserved or marginalized, have access to sexual and reproductive health information and services. Its work is premised on the need to achieve access to and quality of sexual and reproductive health in order to meet the needs of diverse populations, particularly the most vulnerable. It is shaped around the five components of the Global Reproductive Health Strategy of the WHO:

- improving antenatal, perinatal, postpartum, and newborn care;

- providing high-quality services for family planning, including infertility services;

- eliminating unsafe abortion;

- combating sexually transmitted infections, including HIV, reproductive tract infections, cervical cancer, and other sexual and reproductive health morbidities;

- promoting sexual health.

The new director of the WHO Department of RHR and of HRP, Prof. Marleen Temmerman, is a Belgian national who qualified as a medical doctor from Ghent University. She also holds a diploma in tropical medicine from the Institute of Tropical Medicine, Antwerp, an $\mathrm{MPh}$ on epidemiological, statistical, and operational methods applied in public health, a $\mathrm{PhD}$ in obstetrics and gynecology, and a diploma in management. After graduating and working as a gynecologist she moved to Kenya in 1987, where she conducted research into HIV/AIDS

\section{KARGER}

Fax +4161306 1234

E-Mail karger@karger.ch

www.karger.com
(C) 2012 S. Karger AG, Basel

$0378-7346 / 12 / 0743-0185 \$ 38.00 / 0$

Accessible online at: www.karger.com/goi 
and maternal health and was a lecturer at the University of Nairobi. In 1992, she became the first female gynecology professor in Belgium. Currently, Prof. Temmerman is active in a number of fields. She is a member of the independent Expert Review Group, the principal review group on the UN Secretary-General's Commission on Information and Accountability for Women's and Children's Health. Since 2006, she has also served as a senator in the Belgian Parliament where she is member of the Commission on Social Affairs and the Commission on Foreign Affairs. In that capacity she is also a member of the European Parliamentary Forum and chair of the HIV/AIDS Advisory Group of the Inter-Parliamentary Union. Furthermore, she is founder and director of the International Centre for Reproductive Health (ICRH), a WHO collaborating center, based in Belgium, Kenya, and Mozambique. Finally, she is also head of the Obstetrics and Gynaecology Department and member of the board of directors for the Ghent University Hospital. Prof. Temmerman has always fought for improvements in health care of disadvantaged populations and for the reproductive and sexual health and rights of women. Author of over 400 scientific papers and 20 books in three languages, with a wealth of international experience behind her, she will bring her experience in research, medicine, and politics to improve health care to serve the WHO.

The focus of this issue of Gynecologic and Obstetric Investigation is therefore to present an interview with Prof. Temmerman, and to provide information on other activities of the WHO RHR/HRP. One paper describes the background and activities of the WHO Genitourinary Medicine TAG, involved in the development of the ICD11 codes for symptoms and diagnosis in genitourinary disease, including reproductive medicine. Another paper presents the translation into the Dutch language of the WHO ICMART glossary on terms and definitions in assisted reproductive technology. Finally, an overview of 40 years of innovation in the field of sexual and reproductive health research by HRP is provided, as well as a summary of the WHO activities over the last 40 years in reproductive medicine, related to both fertility control (family planning) and infertility prevention and treatment.

Prof. Thomas M. D'Hooghe, Leuven 